\title{
Minireview
}

\section{Highlighting the 'blood-nerve barrier' in virology research}

\author{
ISAMU MORI
}

Faculty of Health and Nutrition, Shubun University, Aichi 491-0938, Japan

Received February 2, 2017; accepted February 20, 2017

\begin{abstract}
Summary. - The blood-nerve barrier (BNB) shields peripheral nerves from the blood in order to maintain the homeostasis of the nervous system. In the field of infectious diseases, little information is currently available concerning the BNB. Recently documented evidence in virology suggests that elevated permeability of the BNB by immune cells and the natural absence of the BNB in the olfactory mucosa play significant roles in neuroprotection as well as neuropathogenesis. Importantly, the BNB can behave more flexibly than previously thought. In the near future, drug delivery via manipulation of the BNB will shed light on new therapeutic and prophylactic strategies for serious and intractable nervous system infections.
\end{abstract}

Keywords: blood-nerve barrier; virus; viremia; antibody; interferon- $\gamma$; olfactory nerve

\section{Contents:}

1. Introduction

2. Immune cells can modulate the $\mathrm{BNB}$ in response to viral infection

3. Olfactory mucosa lacks the BNB

4. Neurotropic viruses can infect the olfactory mucosa via viremia

5. Circulating antiviral antibodies can directly access olfactory neurons

6. Perspectives

\section{Introduction}

The blood-nerve barrier (BNB), equivalent to the bloodbrain barrier of the central nervous system, shields peripheral nerves from the blood, which may contain harmful substances and cells, to maintain the homeostasis of the nervous system (Ubogu, 2013). Thus, the BNB establishes an immunoprivileged site. In principle, the $\mathrm{BNB}$ is organized within the endoneurium by microvascular endothelial cells with electron-dense rich

E-mail: mori.i@shubun.ac.jp; phone: +81-586-45-2101. Abbreviations: $\mathrm{BNB}=$ blood-nerve barrier intercellular tight junctions and lacking fenestrations (Fig. 1). The perineurium protects the endoneurium from passive diffusion of epineurial interstitial fluid components. Active research on the biological functions and pathological involvement of the $\mathrm{BNB}$, in addition to its potential application to drug-delivery systems, however, are far behind corresponding studies of the blood-brain barrier (Bentivoglio and Kristensson, 2014). Consequently, the BNB has attracted comparatively little scientific attention from researchers working in virology. Here, based on recently reported evidence, this review discusses the dynamic actions of various agents in the blood on peripheral nerves under conditions of elevated BNB permeability or the complete absence of the $\mathrm{BNB}$, and propose that the BNB will assume greater importance in virology research in the near future.

\section{Immune cells can modulate the BNB in response to viral infection}

Herpes simplex virus type 2, the major causative agent of genital herpes in humans, infects the mucosal tissue and successively intrudes into innervating neurons of dorsal root ganglia to establish latency. In a recent study, intranasal vaccination with mutant virus harboring a deletion in the 
thymidine kinase gene conferred robust protection against intravaginal challenge with the wild-type virus in mice (Iijima and Iwasaki, 2016). Intranasal immunization generated a circulating memory CD4 T cell pool, but did not establish tissueresident $\mathrm{CD} 4 \mathrm{~T}$ cells in the genital mucosa. Following vaginal challenge with the wild-type virus, mice that were immunized in advance with the mutant virus exhibited insufficient control of viral replication in vaginal mucosa. Nevertheless, viral replication was efficiently blocked in innervating neurons of the dorsal root ganglia. Specifically, circulating memory CD4 T cells migrated rapidly to the dorsal root ganglia and spinal cord in response to vaginal challenge. Interferon- $\gamma$ locally secreted by virus-specific CD4 T cells increased the permeability of the $\mathrm{BNB}$, enabling circulating antiviral antibodies to access neurons. In addition, the blood level of virus-specific antibodies (IgG2b and IgG2c subtypes) positively correlated with protection against wild-type virus. Together, these results demonstrate that circulating memory CD4 T cells, interferon- $\gamma$, and antiviral IgG antibodies cooperatively protect peripheral neurons against neurovirulent virus, thus serving a critical function at the border of the peripheral nervous system, the BNB (Iijima and Iwasaki, 2016).

\section{Olfactory mucosa lacks the BNB}

The olfactory mucosa exhibits unique morphological features not found in other peripheral nerve tissues. First, the den-

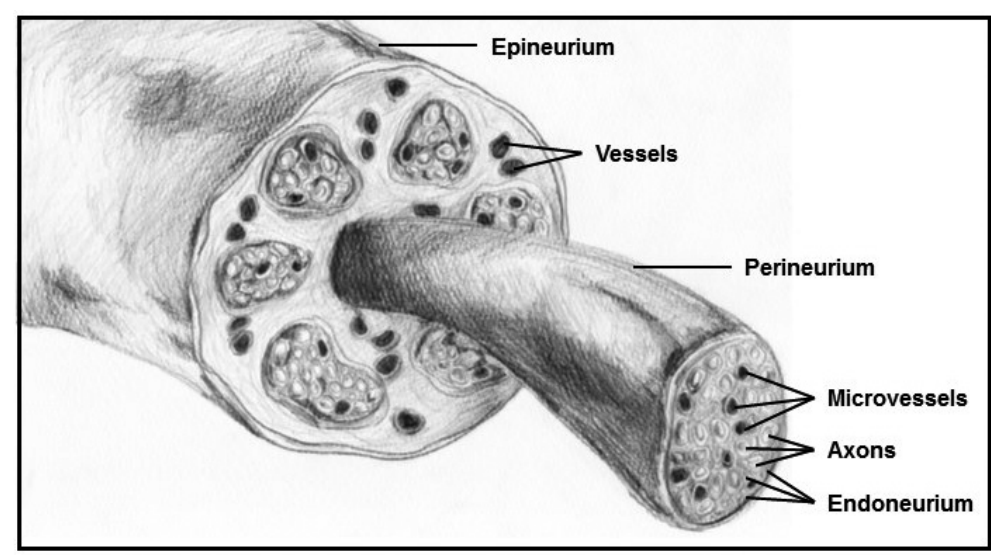

Fig. 1

Anatomy of a typical peripheral nerve

Within the endoneurium, the BNB is formed from the unfenestrated endothelial lining of microvessels with specialized intercellular tight junctions. Axons are myelinated, except in a fraction of sensory and autonomic nerves.

dritic nerve terminals of olfactory neurons are directly exposed to the external environment, i.e., the nasal cavity, so that they can acquire odor stimuli. Second, olfactory neurons form the epithelial structure in concert with sustentacular and basal cells. The olfactory neuroepithelium itself is avascular in postnatal humans (Sangari et al., 2000). Third, beneath the olfactory epithelium is the lamina propria, which is rich in vasculature. An ultrastructural study revealed fenestrations in the endothelial lining of capillaries, mainly in the deeper zone of the lamina propria (Grevers and Herrmann, 1987). Accordingly, unmyelinated axons of olfactory neurons (Blinder et al., 2003) pass through the fenestrated vasculature-rich space and projects to the olfactory bulb (Fig. 2). Such olfactory organization points to an anatomical defect of the BNB. The functional absence of the BNB in the olfactory mucosa has been documented experimentally: in mice, the olfactory mucosa is labeled, within 50 seconds, with intravenously administered horseradish peroxidase (Balin et al., 1986). Bismuth, a neurotoxic xenobiotic metal, readily diffuses from the fenestrated blood vessels of the olfactory mucosa after intraperitoneal injection and accumulates in the vicinity of these microvessels (Ross et al., 1996). Interestingly, the metal travels along the olfactory route centripetally to the olfactory bulb, and further to olfactory-related nuclei such as the amygdala and entorhinal cortex. Collectively, these observations indicate that both biological and pathological factors circulating in the blood can come into direct contact with axons of olfactory neurons.

\section{Neurotropic viruses can infect the olfactory mucosa via viremia}

In experimental settings using animals, a certain set of human arthropod-borne viruses, encompassing La Crosse 


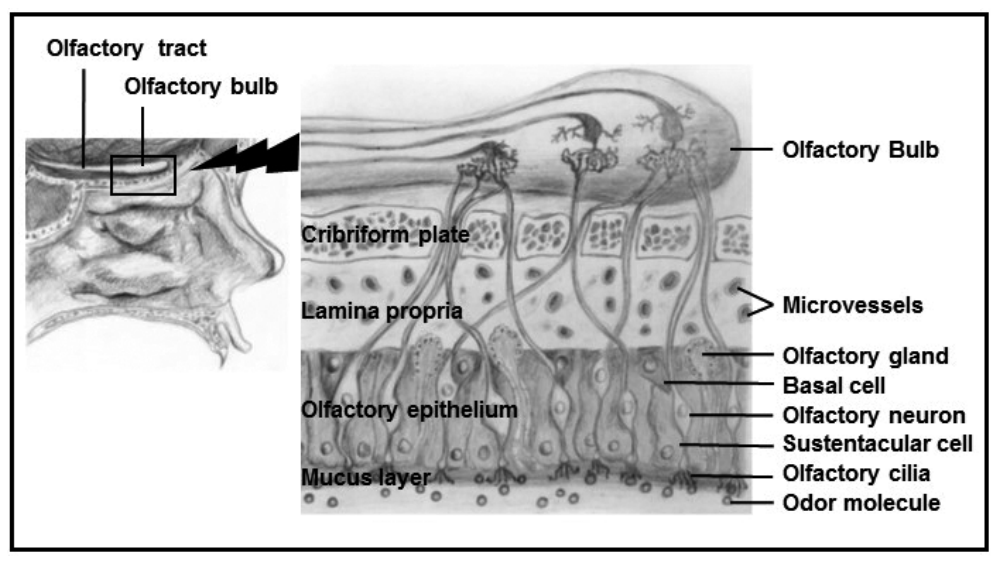

Fig. 2

Anatomy of olfactory mucosa

In the lamina propria, unmyelinated axons of olfactory neurons can be directly exposed to various factors derived from microvessels with fenestrated endothelium. This anatomical organization is compatible with the absence of the BNB in this tissue.

virus, Murray Valley encephalitis virus, St. Louis encephalitis virus, and Venezuelan equine encephalitis virus, infect the olfactory mucosa after intraperitoneal or subcutaneous challenge, most reasonably via the blood stream, and then spread centripetally to the brain (Mori, 2015). These findings support the absence of the BNB in the olfactory mucosa.

A variety of neurotropic viruses are thought to invade the olfactory neurons from dendritic nerve endings. Viruses, however, must overcome the hurdle of the mucus layer covering the luminal surface of the olfactory epithelium (Fig. 2). Considering the findings above, obtained in experimental animals, neurotropic viruses with viremic potential may infect human olfactory mucosa through viremia. In particular, measles virus, Hendra virus, and Nipah virus, all belonging to Paramyxoviridae, West Nile virus and Japanese encephalitis virus, belonging to Flaviviridae, and herpes simplex virus type 1 and human herpesvirus 6 may take this alternative route, leading to sporadic encephalitis (Tyler, 2009; Berrington et al., 2009; Zerr et al., 2006). These viruses can spread via the olfactory pathway to the brain (Mori, 2015). Of note, human herpesvirus-6 DNA is frequently detected in olfactory bulb/ tract tissues obtained from patient autopsies, in which the involvement of viremia is undeniable (Harberts et al., 2011).

A recent study in humans provided the first evidence that influenza virus (seasonal H3N2) enters through the olfactory route (van Riel et al., 2014). The virus was detected in the olfactory bulb, olfactory tract, and gyrus rectus (the gyrus just medial to the olfactory tract). Notwithstanding the apparent olfactory neuroinvasion, the virus was undetectable in other parts of the brain, respiratory tract, and other organs. A plasma sample proved negative for the viral RNA, excluding viremia. By contrast, in a ferret model using highly pathogenic avian influenza $\mathrm{H} 5 \mathrm{~N} 1$ virus, viremia preceded the nervous system infection (Edenborough et al., 2015). Moreover, the $\mathrm{H} 5 \mathrm{~N} 1$ virus reached the olfactory bulb 7 days or later after intranasal infection, providing logical support for the idea of viremic transmission into the olfactory mucosa (Jang et al., 2009). Clinically, viremia induced by pandemic influenza $\mathrm{A} / \mathrm{H} 1 \mathrm{~N} 1 / 2009$ virus is associated with the hemagglutinin D222G/N substitution, and importantly, with high disease severity and mortality (Tse et al., 2011). Taken together, these findings indicate that depending on genotype, influenza viruses may gain entry into the human olfactory system via viremia.

\section{Circulating antiviral antibodies can directly access olfactory neurons}

In a ferret experimental system, homologous vaccination efficiently hindered the CNS invasion by the $\mathrm{H} 5 \mathrm{~N} 1$ virus via the olfactory pathway, whereas prophylactic administration of oseltamivir provided less neuroprotection (Siegers et al., 2016). In that study, ferrets were intramuscularly vaccinated twice with AS03A-adjuvanted H5N1 A/Indonesia/5/05 split vaccine, followed by intranasal challenge with the homologous $\mathrm{H} 5 \mathrm{~N} 1$ virus. In theory, an inactivated vaccine should predominantly induce circulating IgG antibodies against the virus. These antiviral IgG antibodies could leak from fenestrated vessels of the nasal mucosa (Grevers and Herrmann, 1987) and then diffuse to the luminal surface of olfactory epithelium to neutralize the infectivity of the virus. However, such indirectly recruited antiviral antibodies might be insufficient to completely abrogate viral infectivity, because a small amount of infectious virus would remain in the nasal cavity at early time points; consequently, a small fraction of cells in 
the olfactory neuroepithelium might become infected (Siegers et al., 2016). Given the absence of the BNB in the olfactory mucosa, the nearly complete protection of olfactory neurons against the virus may be mediated by abundant virus-specific IgG antibodies coming directly from the bloodstream (Mori, 2016). By contrast, oseltamivir, a neuraminidase inhibitor, blocks the viral enzyme's ability to cleave sialic acid residues on the surface of infected cells, thereby inhibiting progeny virus release. This antiviral event should take place in the olfactory bulb (Fig. 2), which the drug can barely reach because of the presence of the blood-brain barrier.

Another study in a ferret model demonstrated that prophylactic intravenous transfer of the influenza virus $\mathrm{H} 1$ stalk-reactive monoclonal antibodies (IgG2b subtype) significantly decreased the viral titer in the olfactory bulb following challenge with pandemic influenza H1N1 virus (Krammer et al., 2014). This straightforward observation supports the hypothesis that due to the lack of the BNB, circulating IgG antibodies, raised against a viral antigen, directly contact the olfactory neurons to exert their antiviral functions.

Antibody-mediated neuroprotective actions against viruses have been described (Levine et al., 1991; Griffin and Metcalf, 2011), although their precise mechanisms remain to be elucidated. Virus neutralization by antibodies may not be essential for neuroprotection (Srivastava et al., 2015).

\section{Perspectives}

At present, little information regarding the BNB is available in the field of virology. Further accumulation of knowledge concerning the role of the BNB in physiology, pathology, and microbiology will open the door to novel prophylactic as well as therapeutic strategies for intractable nervous system infectious diseases. This is a rather urgent problem given the possibility of future outbreaks of emerging and reemerging infections, exemplified by serious influenza among humans. Antibody therapy as well as vaccination will confer neuroprotection against multiple viruses that favor the olfactory system. Furthermore, drug delivery via artificial manipulation of the $\mathrm{BNB}$ has recently been reported and will be applied in various ways (Sauer et al., 2014; Yang et al., 2016).

Acknowledgment. I thank Haluka Mori for elaborating comprehensible illustrations for this article.

\section{References}

Balin BJ, Broadwell RD, Salcman M, El-Kalliny M (1986): Avenues for entry of peripherally administered protein to the central nervous system in mouse, rat, and squirrel monkey. J. Comp. Neurol. 251, 260-280. https://doi.org/10.1002/ cne. 902510209
Bentivoglio M, Kristensson K (2014): Tryps and trips: cell trafficking across the 100-year-old blood-brain barrier. Trends Neurosci. 37, 325-333. https://doi.org/10.1016/j. tins.2014.03.007

Berrington WR, Jerome KR, Cook L, Wald A, Corey L, Casper C (2009): Clinical correlates of herpes simplex virus viremia amang hospitalized adults. Clin. Infect. Dis. 49, 1295-1301. https://doi.org/10.1086/606053

Blinder KJ, Pumplin DW, Paul DL, Keller A (2003): Intercellular interactions in the mammalian olfactory nerve. J. Comp. Neurol. 466, 230-239. https://doi.org/10.1002/ cne. 10872

Edenborough KM, Lowther S, Laurie K, Yamada M, Long F, Bingham J, Payne J, Harper J, Haining J, Arkinstall R, Gilbertson B, Middleton D, Brown LE (2015): Predicting disease severity and viral spread of $\mathrm{H} 5 \mathrm{~N} 1$ influenza virus in ferrets in the context of natural exposure routes. J. Virol. 90, 1888-1897. https://doi.org/10.1128/JVI.01878-15

Grevers G, Herrmann U (1987): Fenestrated endothelia in vessels of the nasal mucosa. An electron-microscopic study in the rabbit. Arch. Otorhinolaryngol. 244, 55-60. https:// doi.org/10.1007/BF00453492

Griffin DE, Metcalf T (2011): Clearance of virus infection from the CNS. Curr. Opin. Virol. 1, 216-221. https://doi. org/10.1016/j.coviro.2011.05.021

Harberts E, Yao K, Wohler JE, Maric D, Ohayon J, Henkin R, Jacobson S (2011): Human herpesvirus-6 entry into the central nervous system through the olfactory pathway. Proc. Natl. Acad. Sci. USA 108, 13734-13739. https:// doi.org/10.1073/pnas.1105143108

Iijima N, Iwasaki A (2016): Access of protective antiviral antibody to neuronal tissues requires CD4 T-cell help. Nature 533, 552-556. https://doi.org/10.1038/nature17979

Jang H, Boltz D, Sturm-Ramirez K, Shepherd KR, Jiao Y, Webster R, Smeyne RJ (2009): Highly pathogenic H5N1 influenza virus can enter the central nervous system and induce neuroinflammation and neurodegeneration. Proc. Natl. Acad. Sci. USA 106, 14063-14068. https://doi. org/10.1073/pnas.0900096106

Krammer F, Hai R, Yondola M, Tan GS, Leyva-Grado VH, Ryder AB, Miller MS, Rose JK, Palese P, Garcia-Sastre A, Albrecht RA (2014): Assessment of influenza virus hemagglutinin stalk-based immunity in ferrets. J. Virol. 88, 3432-3442. https://doi.org/10.1128/JVI.03004-13

Levine B, Hardwick JM, Trapp BD, Crawford TO, Bollinger RC, Griffin DE (1991): Antibody-mediated clearance of alphavirus infection from neurons. Science 254, 856-860. https://doi.org/10.1126/science. 1658936

Mori I (2015): Transolfactory neuroinvasion by viruses threatens the human brain. Acta Virol. 59, 338-349. https://doi. org/10.4149/av $2015 \quad 04 \quad 338$

Mori I (2017): Vaccination effectively prevents central nervous system invasion by influenza $\mathrm{A}(\mathrm{H} 5 \mathrm{~N} 1)$ virus through the olfactory pathway: a proposed mechanism of neuroprotection. J. Infect. Dis. 215, 159-160. https://doi. org/10.1093/infdis/jiw473

Ross JF, Switzer RC, Poston MR, Lawhorn GT (1996): Distribution of bismuth in the brain after intraperitoneal dosing 
of bismuth subnitrate in mice: implications for routes of entry of xenobiotic metals into the brain. Brain Res. 725, 137-154. https://doi.org/10.1016/0006-8993(96)00146-1

Sangari SK, Sengupta P, Pradhan S, Khatri K (2000): Vasculization of developing human olfactory neuroepithelium - a morphometric study. Cells Tissues Organs 166, 349-353. https://doi.org/10.1159/000016750

Sauer RS, Krug SM, Hackel D, Staat C, Konasin N, Yang S, Niedermirtl B, Bosten J, Günther R, Dabrowski S, Doppler K, Sommer C, Blasig IE, Brack A, Rittner HL (2014): Safety, efficacy, and molecular mechanism of claudin-1-specific peptides to enhance blood-nerve-barrier permeability. J. Control Release 185, 88-98. https://doi.org/10.1016/j. jconrel.2014.04.029

Siegers JY, van den Brand JM, Leijten LM, van de Bildt MM, van Run PR, van Amerongen G, Stittelaar KJ, Koopmans MP, Osterhaus AD, Kuiken T, van Riel D (2016): Vaccination is more effective than prophylactic oseltamivir in preventing CNS invasion by $\mathrm{H} 5 \mathrm{~N} 1$ virus via the olfactory nerve. J. Infect. Dis. 214, 516-524. https://doi.org/10.1093/ infdis/jiw123

Srivastava R, Ramakrishna C, Cantin E (2015): Anti-inflammatory activity of intravenous immunoglobulins protects against West Nile virus encephalitis. J. Gen. Virol. 96, 1347-1357. https://doi.org/10.1099/vir.0.000079
Tse H, To KK, Wen X, Chen H, Chan KH, Tsoi HW, Li IW, Yuen KY (2011): Clinical and virological factors associated with viremia in pandemic influenza $\mathrm{A} / \mathrm{H} 1 \mathrm{~N} 1 / 2009$ virus infection. PLoS One 6, e22534. https://doi.org/10.1371/ journal.pone.0022534

Tyler KL (2009): Emerging viral infections of the central nervous system. Arch. Neurol. 66, 1065-1074.

Ubogu EE (2013): The molecular and biophysical characterization of the human blood-nerve barrier: current concepts. J. Vasc. Res. 50, 289-303. https://doi.org/10.1159/000353293

van Riel D, Leijten LM, Verdijk RM, GeurtsvanKessel C, van der Vries E, van Rossum AM, Osterhaus AD, Kuiken T (2014): Evidence for influenza virus CNS invasion along the olfactory route in an immunocompromised infant. J. Infect. Dis. 210, 419-423. https://doi.org/10.1093/infdis/jiu097

Yang S, Krug SM, Heitmann J, Hu L, Reinhold AK, Sauer S, Bosten J, Sommer C, Fromm M, Brack A, Rittner HL (2016): Analgesic drug delivery via recombinant tissue plasminogen activator and microRNA-183-triggered opening of the blood-nerve barrier. Biomaterials 82, 20-33. https://doi. org/10.1016/j.biomaterials.2015.11.053

Zerr DM, Frenkel LM, Huang ML, Rhoads M, Nguy L, Del Beccaro MA, Corey L (2006): Polymerase chain reaction diagnosis of primary human herpesvirus- 6 infection in the acute care setting. J. Pediatr. 149, 480-485. https:// doi.org/10.1016/j.jpeds.2006.05.027 